\title{
Transactions
}

Cite this: Dalton Trans., 2011, 40, 9925

wWW.rsc.org/dalton

PAPER

\section{Isomeric separation in donor-acceptor systems of Pd(II) and Pt(II) and a combined structural, electrochemical and spectroelectrochemical study $\dagger$}

\author{
Naina Deibel, ${ }^{a}$ David Schweinfurth, ${ }^{a}$ Jan Fiedler, ${ }^{b}$ Stanislav Záliš ${ }^{b}$ and Biprajit Sarkar*a \\ Received 6th May 2011, Accepted 18th July 2011 \\ DOI: 10.1039/c1dt10856e
}

Compounds of the form [(pap) $\left.\mathrm{M}\left(\mathrm{Q}^{2-}\right)\right]$ (pap = phenylazopyridine; $\mathrm{Q}=3$,5-di-tert-butyl-benzoquinone, $\mathbf{M}=\mathbf{P d}, \mathbf{1} \mathbf{a}$ and $\mathbf{1 b}, \mathbf{M}=\mathrm{Pt}, \mathbf{2} \mathbf{a}$ and $\mathbf{2 b} ; \mathrm{Q}=4$-tert-butyl-benzoquinone, $\mathrm{M}=\mathrm{Pd}$, 3a and $\mathbf{3 b} ; \mathbf{M}=\mathrm{Pt}, \mathbf{4 a}$ and $\mathbf{4 b}$ ) were synthesized in a one-pot reaction. The geometrical isomers, which are possible because of the built in asymmetry of these ligands, have been separated by using different temperatures and variable solubility. Structural characterization of $\mathbf{1 b}$ shows that the metal centers are in a square planar environment, the pap ligand is in the unreduced neutral state and the quinones are in the doubly reduced, $\mathrm{Q}^{2-}$ catecholate form. Cyclic voltammetric measurements on the complexes display two one-electron oxidations and two one-electron reductions. EPR and vis-NIR spectra of the one-electron oxidized forms of the complexes indicate that the first oxidation takes place on the $\mathrm{Q}^{2-}$ ligands to produce a metal bound semiquinone $\left(\mathrm{Q}^{--}\right)$radical. Reduction takes place on the pap ligand, generating metal bound pap ${ }^{--}$as seen from the ${ }^{14} \mathrm{~N}(I=1)$ coupling in their EPR spectrum. All the complexes in their $\left[(\right.$ pap $\left.) \mathrm{M}\left(\mathrm{Q}^{2-}\right)\right]$ neutral forms show strong absorptions in the NIR region which are largely LLCT (ligand to ligand charge transfer) in origin. These NIR bands can be tuned over a wide energy range by varying the metal center as well as the $\mathrm{Q}$ ligand. In addition, the intensity of NIR bands can be switched on and off by a simple electron transfer at relatively low potentials. DFT studies were used to corroborate these findings.

\section{Introduction}

Donor-acceptor systems based on Pt(II) and containing redox non-innocent ligands have been studied for a while because of their exciting photochemical properties and their possible use in harnessing solar energy. ${ }^{1-7}$ After initial studies, which were based mainly on dithiolates as donors and diimines as acceptors, recent focus has also been on other related redox-active donors. ${ }^{8-17}$ In this regard we recently reported on the isomeric separation in complexes of the form $\left[(\operatorname{pap}) \mathrm{Pt}\left(\mathrm{Q}^{2-}\right)\right]$ (pap = phenylazopyridine, $\mathrm{Q}=3$,5-di-tert-butyl-benzoquinone). ${ }^{18}$ The quinones, $\mathrm{Q}$ can exist in the three different redox forms of $\mathrm{Q}^{0}, \mathrm{Q}^{--}$and $\mathrm{Q}^{2-}$ which are connected by one-electron transfer processes. The ligand pap which contains an azo group ${ }^{19}$ can also exist as pap $^{0}$, pap $^{--}$or pap $^{2-}$. Non-innocent behavior of such ligands has been studied in various metal complexes. ${ }^{20-30}$ In view of our interest in the chemistry of quinone ligands ${ }^{31-37}$ and building up donor-acceptor

anstitut für Anorganische Chemie, Universität Stuttgart, Pfaffenwaldring 55,D-70550,Stuttgart,Germany.E-mail:sarkar@iac.uni-stuttgart.de

${ }^{b} J$. Heyrovsky Institute of Physical Chemistry, v.v.i., Academy of Sciences of the Czech Republic, Dolejškova 3, CZ-18223, Prague, Czech Republic

$\dagger$ Electronic supplementary information (ESI) available. CCDC reference numbers 805489. For ESI and crystallographic data in CIF or other electronic format see DOI: 10.1039/c1dt10856e systems based on them, ${ }^{38}$ we looked into systems [(pap) $\left.\mathrm{Pt}\left(\mathrm{Q}^{2-}\right)\right]$ which resulted in our preliminary report on isomer separation. ${ }^{18}$ Encouraged by our initial results we decided to systematically probe the phenomenon of isomer formation in such complexes and also extended this work to include an additional Q ligand as well as to $\mathrm{Pd}(\mathrm{II})$ complexes. Herein we report on the synthesis and isomer separation of $\left[(\right.$ pap $\left.) \mathrm{M}\left(\mathrm{Q}^{2-}\right)\right]$ (pap = phenylazopyridine; $\mathrm{Q}=$ 3,5-di-tert-butyl-benzoquinone, $\mathrm{M}=\mathrm{Pd}$, $\mathbf{1 a}$ and $\mathbf{1 b}, \mathbf{M}=\mathrm{Pt}$, $\mathbf{2 a}$ and $\mathbf{2 b}$; $\mathrm{Q}=4$-tert-butyl-benzoquinone, $\mathrm{M}=\mathrm{Pd}$, $\mathbf{3} \mathbf{a}$ and $\mathbf{3 b}$; $\mathbf{M}=\mathrm{Pt}, \mathbf{4} \mathbf{a}$ and $\mathbf{4 b}$ ). The separation of the isomers was achieved by either varying the reaction temperature or by preferentially precipitating one isomer. Structural characterization of some of the complexes helped in isomer identification. Compounds of the form mentioned here have been reported in the literature. However, no mention of isomer formation or separation can be found in those reports. ${ }^{13,39}$ We have also investigated the complexes electrochemically to probe their redox properties. A combined vis-NIR and EPR spectroelectrochemical study is presented to elucidate the spectroscopic properties of these complexes. Control of absorptions in the NIR region is another aspect of this work and we show here that such absorptions, which can be useful for future opto-electronic systems ${ }^{40,41}$ can be tuned by varying the metal centre as well as the quinone ligand. In addition, controlling of the intensity of such NIR absorptions via electron transfer is also presented. 


\section{Results and discussion}

\section{Synthesis and crystal structure}

The complexes (Scheme 1) were synthesized in a one-pot reaction by using $\mathrm{Pd}$ (pap) $\mathrm{Cl}_{2}$ or $\mathrm{Pt}$ (pap) $\mathrm{Cl}_{2}$ and the relevant $\mathrm{QH}_{2}$ ligand with $\mathrm{NEt}_{3}$ as a base in acetonitrile (Experimental section). Encouraged by our finding that isomer separation is possible in such complexes, ${ }^{18}$ we systematically varied the reaction conditions in order to be able to force the formation of one isomer or the other based on reaction conditions. After screening a set of conditions, we were delighted to find that temperature, time and solubility are the factors that can result in the favorable formation of one isomer or the other. Thus carrying out the reaction for $3 \mathrm{~h}$ at room temperature results in the preferential formation of $\mathbf{1 a}$ or 3a (kinetic control). On refluxing the solution at $70{ }^{\circ} \mathrm{C}$, the other isomer, $\mathbf{1 b}$ or $\mathbf{3 b}$ is formed preferentially (thermodynamic control, Scheme 1 and Experimental section). For the platinum complexes, solubility differences were used for separation of $\mathbf{4 a}$ from $\mathbf{4 b}$. This is in contrast to our earlier finding where we had achieved isomer separation exclusively through column chromatography. ${ }^{18}$ The metal complexes were characterized by ${ }^{1} \mathrm{H}$ NMR spectroscopy, elemental analyses and mass spectrometry. ${ }^{1} \mathrm{H}$ NMR spectroscopy can be put to good use to check the formation of one isomer or the other (Experimental section, Figure S1 $\dagger$ ).
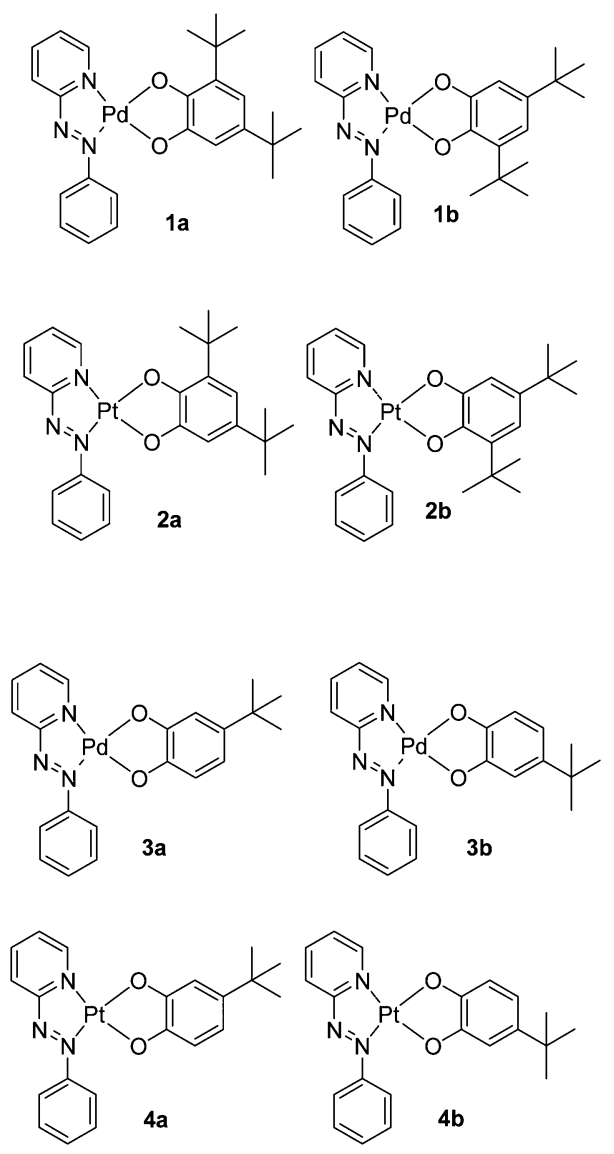

Scheme 1 Isomers of the complexes reported in this work.

1b could be crystallized by slow evaporation of a $\mathrm{CH}_{2} \mathrm{Cl}_{2}$ solution of it layered with $n$-hexane for single crystal X-ray
Table 1 Crystallographic details

\begin{tabular}{ll}
\hline Chemical formula & $\mathrm{C}_{25} \mathrm{H}_{29} \mathrm{~N}_{3} \mathrm{O}_{2} \mathrm{Pd}$ \\
$M_{\mathrm{r}}$ & 509.91 \\
Crystal system, space group & Triclinic, $P \overline{1}$ \\
$T / \mathrm{K}$ & 173 \\
$a, b, c / \AA$ & $6.9087(4), 10.8143(7), 15.7231(9)$ \\
$\alpha, \beta, \gamma\left({ }^{\circ}\right)$ & $101.526(3), 97.418(3), 91.407(3)$ \\
$V / \AA^{3}$ & $1139.86(12)$ \\
$Z$ & 2 \\
Density/g cm & -3 \\
F000 & 1.486 \\
Radiation type & 524 \\
$\mu / \mathrm{mm}^{-1}$ & $\mathrm{Mo-K} \alpha$ \\
Crystal size $/ \mathrm{mm}$ & 0.84 \\
meas. refl. & $0.15 \times 0.05 \times 0.01$ \\
indep. refl. & 9621 \\
obsvd. $[I>2 \sigma(I)]$ refl. & 4081 \\
$R_{\text {int }}$ & 3484 \\
$R\left[F^{2}>2 \sigma\left(F^{2}\right)\right], w R\left(F^{2}\right), S$ & 0.117 \\
$\Delta \rho_{\text {max }}, \Delta \rho_{\min } / \mathrm{e} \AA^{-3}$ & $0.081,0.221,1.034$ \\
\hline
\end{tabular}

diffraction studies. This result was used for the unambiguous identification of the configuration of the isomers. The same was previously done by us for $\mathbf{2 a}$ and $\mathbf{2 b}$. For $\mathbf{3 a} / \mathbf{3 b}$ and $\mathbf{4 a} / \mathbf{4 b}$, isomer identification was done by comparing their ${ }^{1} \mathrm{H}-\mathrm{NMR}$ spectra with those of $\mathbf{1 a} / \mathbf{1 b}$ and $\mathbf{2 a} / \mathbf{2} \mathbf{b}$ respectively (Figure $\mathrm{S} 1 \dagger$ ). Crystallographic details for $\mathbf{1 b}$ are presented in Table 1. 1b crystallizes in the triclinic $P \overline{1}$ space group (Fig. 1).

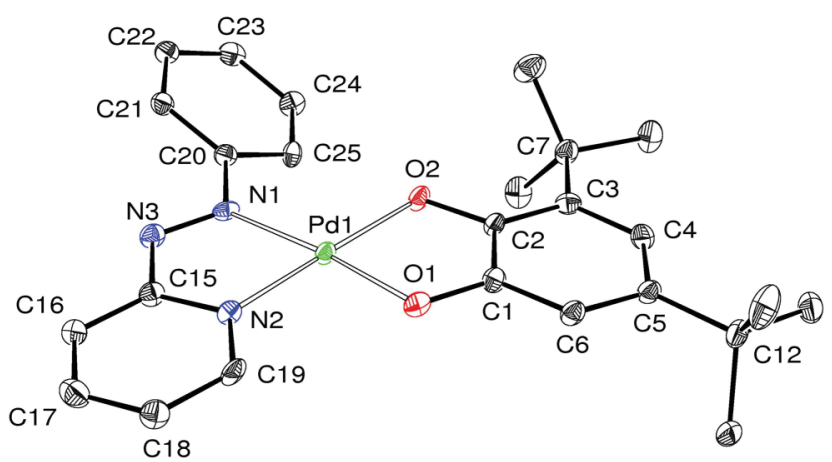

Fig. 1 ORTEP plot of 1b. Ellipsoids are drawn at 30\% probability. Hydrogen atoms are omitted for clarity.

The Pd(II) center in $\mathbf{1 b}$ adopts a distorted square planar environment, the distortion being imposed by the chelating nature of the pap and Q ligands. This is evident from the O1-Pd1-O2 angle of $83.6(2)^{\circ}$ and $\mathrm{N} 1-\mathrm{Pd} 1-\mathrm{N} 2$ of $78.3(2)^{\circ}$ respectively. The $\mathrm{Pd}-\mathrm{N}$ and $\mathrm{Pd}-\mathrm{O}$ distances are in the expected range. Bond length analyses within the $\mathrm{Q}$ ring clearly establish its completely reduced $\mathrm{Q}^{2-}$ catecholate form. Thus the $\mathrm{C} 1-\mathrm{O} 1$ and $\mathrm{C} 2-\mathrm{O} 2$ distances of 1.331(9) and 1.351(9) $\AA$ respectively point to $\mathrm{C}-\mathrm{O}$ single bond distances. The virtually identical intra-ring $\mathrm{C}-\mathrm{C}$ bond distances and their average values of about $1.4 \AA$ suggests the aromatic character of the ring as would be expected for a catecholate form. ${ }^{21,22}$ The distances within the pap ring are typical for the unreduced and neutral pap $^{0}$ form (Fig. 1). The slightly elongated $\mathrm{N}-\mathrm{N}$ distance of 1.286(9) $\AA$ compared to an authentic $\mathrm{N}=\mathrm{N}$ double bond has to do with back-donation from the $\operatorname{Pd}(\mathrm{II})$ center which is bonded to the electron-rich $\mathrm{Q}^{2-}$ ligand. ${ }^{19,42,43}$ Bond length analyses thus show that the best formulation for $\mathbf{1 b}$ is $\left[\left(\operatorname{pap}^{0}\right) \operatorname{Pd}\left(\mathrm{Q}^{2-}\right)\right]$. The data presented here match well with our 
previous report on the structural parameters of the platinum complexes $\mathbf{2 a}$ and $\mathbf{2 b}{ }^{18}$ The uncoordinated phenyl ring of pap is twisted with respected to the rest of the molecule. This is apparent from the dihedral angle of $31.2^{\circ}$ between the planes defined by the phenyl ring and the $\mathrm{Pd}$ (II) center together with its coordinating atoms. The twisting of the phenyl ring is most likely a result of either steric repulsion between the $\mathrm{C}-\mathrm{H}$ bond of the phenyl and the adjacent coordinating $\mathrm{O}$ atom of the $\mathrm{Q}^{2-}$ ring or packing effects in the solid state.

Various attempts at crystallizing the isomer 1a invariably led to the isolation of the crystals of $\mathbf{1 b}$. The conversion was independently verified by performing ${ }^{1} \mathrm{H}$ NMR experiments on 1a before the crystallization process and then measuring a ${ }^{1} \mathrm{H}$ NMR spectrum of the resulting crystals (Figure S2 $\uparrow$ ). From the synthetic protocols of the isomers (vide supra) it is known that $\mathbf{1 b}$ is the thermodynamically stable form. Hence over the period of crystallization in solution, 1a is converted to the thermodynamically stable product $\mathbf{1 b}$. This phenomenon was not observed for the platinum complexes $\mathbf{2} \mathbf{a} / \mathbf{2 b}$, for which we had reported the crystal structures of both the isomers previously. With comparable ligands, platinum is known to form more robust bonds than palladium. This fact is possibly responsible for the conversion of $1 \mathbf{a}$ to $\mathbf{1 b}$ over a period of time but not of $\mathbf{2 a}$ to $\mathbf{2 b}$.

\section{Cyclic voltammetry}

The presence of two redox-active ligands makes the complexes presented here ideal candidates for cyclic voltammetric measurements. Each of the complexes described in this work show two oxidation and two reduction processes within the dichloromethane solvent window. Both isomers of each complex were investigated electrochemically in $\mathrm{CH}_{2} \mathrm{Cl}_{2} / 0.1 \mathrm{M} \mathrm{Bu}_{4} \mathrm{NPF}_{6}$. However, as expected, and as can be seen from Table 2, their behavior is virtually identical and hence in the following, the discussion will be restricted to one set of isomers. All the complexes show a completely reversible first one-electron oxidation at relatively low potentials (Fig. 2 and, Table 2). The Pd(II) complexes 1a $\left(E_{1 / 2}{ }^{\mathrm{ox} 1}=-0.37 \mathrm{~V}\right)$ and $3 \mathbf{a}\left(E_{1 / 2}{ }^{\mathrm{ox}}=-0.30 \mathrm{~V}\right)$ are respectively easier to oxidize compared to their $\mathrm{Pt}(\mathrm{II})$ analogues $2 \mathrm{a}\left(E_{1 / 2}{ }^{\circ \times 1}=0.14 \mathrm{~V}\right)$ and $4 \mathbf{a}\left(E_{1 / 2}{ }^{\circ \times 1}=0.22 \mathrm{~V}\right)$. The difference in the first oxidation
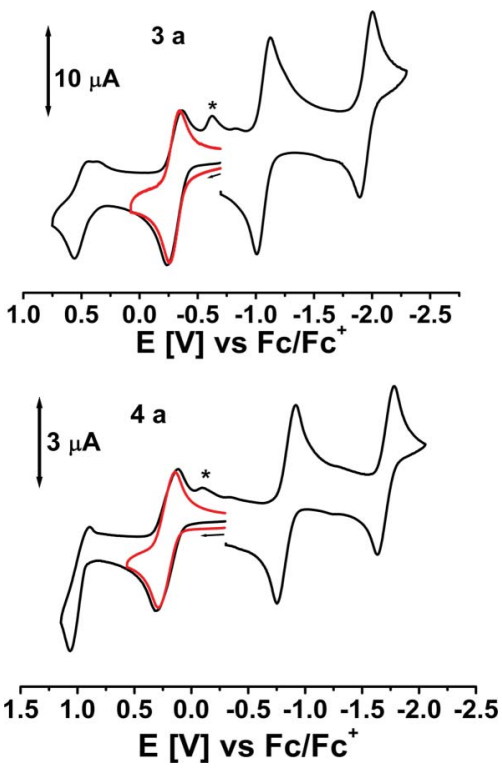

Fig. 2 Cyclic voltammogram of $\mathbf{3 a}$ and $\mathbf{4 a}$ in $\mathrm{CH}_{2} \mathrm{Cl}_{2} / 0.1 \mathrm{M} \mathrm{Bu}_{4} \mathrm{NPF}_{6}$ at $298 \mathrm{~K} . *$ corresponds to a re-reduction peak that appears after the $2 \mathrm{nd}$ oxidation. The red curves show the reversibility of the first oxidation step when the scan direction is reversed without scanning the second oxidation step.

potentials of 1a and 2a is about $500 \mathrm{mV}$. This result is a first indication of some amount of metal influence in the first oxidation process. The first oxidation potential of the reported complexes $\left[(\mathrm{Q}) \mathrm{Pt}\left(\mathrm{bpy}^{*}\right)\right]^{8}$ and $[(\mathrm{Q}) \mathrm{Pt}(\mathrm{dpphen})]^{9}$ (bpy* $=4,4^{\prime}$-(di-tert-butyl)2,2'-bipyridine, dpphen $=4,7$-diphenyl-1,10-phenanthroline) are cathodically shifted compared to $\mathbf{2 a}$ (Table 2). This can be rationalized by considering the better $\pi$-accepting ability of pap compared to bpy* or dpphen. The second oxidation is irreversible for all the reported complexes at all tested temperatures ( -50 to $25{ }^{\circ} \mathrm{C}$ ) and scan rates $\left(50\right.$ to $\left.1000 \mathrm{mV} \mathrm{s}^{-1}\right)$. This phenomenon was also observed for $\left[(\mathrm{Q}) \mathrm{Pt}\left(\mathrm{bpy}^{*}\right)\right]$ and $[(\mathrm{Q}) \mathrm{Pt}(\mathrm{dpphen})]$. A likely explanation is the extremely weak basicity of the neutral $o$-quinone form, $\mathrm{Q}^{0}$ that is generated on second oxidation. The weak basicity probably leads to complex dissociation and hence makes the second oxidation irreversible. The irreversibility of the second

Table 2 Electrochemical data from cyclic voltammetry ${ }^{a}$

\begin{tabular}{|c|c|c|c|c|c|c|}
\hline Compounds & $E^{0 \times 2, b}$ & $E^{\mathrm{ox} 1}$ & $E^{\mathrm{red} 1}$ & $E^{\mathrm{red} 2}$ & $K_{\mathrm{c}}^{\mathrm{neu}, c}$ & $K_{\mathrm{c}}^{\mathrm{red}, d}$ \\
\hline $1 \mathbf{a}$ & 0.45 & -0.37 & -1.12 & -1.99 & $5 \times 10^{12}$ & $6 \times 10^{14}$ \\
\hline $1 \mathrm{~b}$ & 0.55 & -0.30 & -1.04 & -1.90 & $5 \times 10^{12}$ & $6 \times 10^{14}$ \\
\hline $2 \mathbf{b}^{18}$ & 0.93 & 0.12 & -0.94 & -1.75 & $9 \times 10^{17}$ & $5 \times 10^{13}$ \\
\hline $3 \mathbf{a}$ & 0.48 & -0.30 & -1.07 & -1.95 & $1 \times 10^{13}$ & $8 \times 10^{14}$ \\
\hline 3b & 0.51 & -0.25 & -1.03 & -1.90 & $1 \times 10^{13}$ & $5 \times 10^{14}$ \\
\hline $4 a$ & 1.08 & 0.22 & -0.82 & -1.70 & $4 \times 10^{17}$ & $8 \times 10^{14}$ \\
\hline$\left[\mathrm{Pt}(\mathrm{Q})(\mathrm{dpphen}){ }^{f, 8}\right.$ & 0.56 & -0.07 & -1.66 & -2.28 & $9 \times 10^{26}$ & $3 \times 10^{10}$ \\
\hline$\left[\mathrm{Pd}(\text { pap }) \mathrm{Cl}_{2}\right]^{\mathrm{g}, 44}$ & n.o. & n.o. & -0.56 & $-1.39^{h}$ & - & - \\
\hline$\left[\mathrm{Pt}(\text { pap }) \mathrm{Cl}_{2}\right]^{44}$ & n.o. & n.o. & -0.79 & -1.74 & - & $1 \times 10^{16}$ \\
\hline
\end{tabular}

${ }^{a}$ Half-wave potentials from cyclic voltammetric measurements in $\mathrm{CH}_{2} \mathrm{Cl}_{2} / 0.1 \mathrm{M} \mathrm{Bu}_{4} \mathrm{NPF}_{6}$ for reversible processes at $298 \mathrm{~K}$, scan rate $100 \mathrm{mV} \mathrm{s}{ }^{-1}$, ferrocene/ferrocenium was used as an internal standard. ${ }^{b} E_{\mathrm{pa}}$ for irreversible process. ${ }^{c} K_{\mathrm{c}}^{\text {neu }}=10^{\Delta E \text { neu } / 59 \mathrm{mV}}, \Delta E^{\text {neu }}=E^{\text {oxi }}-E^{\text {red1 }} .{ }^{d} K_{\mathrm{c}}{ }^{\text {red }}=10^{\Delta E \text { red } / 59 \mathrm{mV}}, \Delta E^{\text {red }}=$ $E^{\text {red1 }}-E^{\text {red2 }} .{ }^{e} \mathrm{Q}=3,5$-di-tert-butyl-catecholate, bpy* $=4,4^{\prime}$-(di-tert-butyl)-2,2 ${ }^{\prime}$-bipyridine. ${ }^{f}$ dpphen $=4,7$-diphenyl-1,10-phenanthroline. ${ }^{g}$ measurements at $253 \mathrm{~K} .{ }^{h} E_{\mathrm{pc}}$ for irreversible reduction. n.o. = not observed. 
oxidation process precluded the quantitative determination of the thermodynamic stability of the one-electron oxidized form.

Both the reduction processes are completely reversible for the complexes reported here. The large differences between the first oxidation and first reduction potentials lead to comproportionation constant $\left(K_{\mathrm{c}}\right)$ values of the order of $10^{12}$ for the palladium complexes $\mathbf{1 a}$ and $\mathbf{3 a}$, and $10^{17}$ for the platinum complexes $\mathbf{2 a}$ and $\mathbf{4 a}$, showing their high thermodynamic stability. Just like the oxidation processes, the reduction potentials for the palladium complexes 1a $\left(E_{1 / 2}^{\text {redl }}=-1.12 \mathrm{~V}\right)$ and $3 \mathbf{a}\left(E_{1 / 2}^{\text {redl }}=-1.07 \mathrm{~V}\right)$ are cathodically shifted compared to their platinum analogues 2a $\left(E_{1 / 2}{ }^{\text {redl }}=-0.90 \mathrm{~V}\right)$ and $4 \mathbf{a}\left(E_{1 / 2}{ }^{\text {redl }}=-0.82 \mathrm{~V}\right)$; the shift, however, is less compared to that for the oxidation potentials (Table 2). The trend in the reduction potentials observed here is the opposite of what was observed for the precursor complexes $\left[\mathrm{Pd}(\mathrm{pap}) \mathrm{Cl}_{2}\right]$ and $\left[\mathrm{Pt}(\mathrm{pap}) \mathrm{Cl}_{2}\right],{ }^{44}$ where the $\mathrm{Pd}(\mathrm{II})$ complex $\left(E_{1 / 2}=\right.$ $-0.56 \mathrm{~V})$ has a lower negative reduction potential compared to that of the $\mathrm{Pt}(\mathrm{II})$ analogue $\left(E_{1 / 2}=-0.79 \mathrm{~V}\right)$. $\mathrm{Pd}$ (II) is normally capable of a better $\sigma$-polarization effect compared to $\mathrm{Pt}(\mathrm{II})$ and this phenomenon is responsible for the lower negative reduction potential of $\left[\mathrm{Pd}(\right.$ pap $\left.) \mathrm{Cl}_{2}\right]$ compared to $\left[\mathrm{Pt}(\mathrm{pap}) \mathrm{Cl}_{2}\right]$. In the present case, this trend is likely reversed because of the superior donor ability of the $\left[\mathrm{Pd}(\mathrm{Q})^{2-}\right]$ unit containing the $\mathrm{Q}^{2-}$ ligand in $\mathbf{1 a}$ and 3a, thus leading to shift of reduction potentials to higher negative values. The same phenomenon is also responsible for the cathodic shift of all reduction potentials of 1a-4a compared to the precursor complexes $\left[\mathrm{Pd}(\mathrm{pap}) \mathrm{Cl}_{2}\right]$ and $\left[\mathrm{Pt}(\mathrm{pap}) \mathrm{Cl}_{2}\right] .^{44}$ It should be noted here that for a series of related $\mathrm{Pd}(\mathrm{II})$ and $\mathrm{Pt}(\mathrm{II})$ complexes, reported with 2,2'-bipyridine (bpy) and catecholate, amidophenolate, amidothiolate or dithiolate ligands, the reduction potentials were shown to be independent of the metal centers as well as the donor ligands. ${ }^{15}$ The $\pi^{*}$-LUMO of the bpy ligands are energetically much higher compared to the $\pi^{*}$-LUMO of pap. Thus, in the complexes with bpy, the effect of the $\left[\mathrm{M}(\mathrm{Q})^{2-}\right]$ fragment on the reduction potentials for the bpy centered process is negligible.
The reduction potentials of $\left[\mathrm{Pt}(\mathrm{Q})\left(\mathrm{bpy}^{*}\right)\right]^{9}$ and $[\mathrm{Pt}(\mathrm{Q})(\mathrm{dpphen})]^{8}$ are shifted to higher negative values compared to $\mathbf{2 a}$ (Table 2). This can be rationalized by the energetically lower lying $\pi^{*}$-LUMO of pap compared to bpy* or dpphen. The large differences between the 1st and 2 nd reduction potentials for all the complexes leads to a very high thermodynamic stability of the one-electron reduced forms, as seen from the comproportionation constant values $\left(K_{\mathrm{c}}\right)$ of the order of $10^{14}$ (Table 2). The effect of the tert-butyl groups (one or two) of $\mathrm{Q}$, on the redox potentials of the complexes is negligible. In order to gain further insight into the redox steps, visNIR as well as EPR spectroelectrochemical studies were carried out on the complexes. Since positional isomers such as the ones described here are known to have virtually identical spectroscopic properties, only one isomer was investigated with these methods.

\section{Vis-NIR spectroelectrochemistry}

All the investigated complexes show intense absorption bands in the NIR region and this band dominates their absorption spectrum (Fig. 3 and 4, Table 3). For the Pd(II) complexes, the NIR band is shifted to lower energies compared to their Pt(II) counterparts [1378 nm $\left(7256 \mathrm{~cm}^{-1}\right)$ for $\mathbf{1 b}$ versus $970 \mathrm{~nm}\left(10309 \mathrm{~cm}^{-1}\right)$ for 2b]. The origin of this band lies in the spin and dipole allowed LLCT (with some MLCT contribution) transition from a highest occupied molecular orbital (HOMO) predominantly based on the $\mathrm{Q}^{2-}$ donor to the lowest unoccupied molecular orbital (LUMO) located primarily on the pap ligand as has been confirmed by TD-DFT calculations (vide infra). The position of this band correlates well with the difference between the first oxidation and first reduction potentials of the complexes as obtained from cyclic voltammetry experiments (Table 2 and 3). All the complexes display further bands in the visible region which can be assigned to metal to ligand charge transfer (MLCT, $\mathrm{M}(\mathrm{d} \pi) \rightarrow \operatorname{pap}\left(\pi^{*}\right)$ ) and intra ligand (IL) transitions. Some of these bands are reminiscent

Table 3 vis-NIR data of the complexes in various redox forms ${ }^{a}$

\begin{tabular}{|c|c|}
\hline Compound & $\lambda / \mathrm{nm}\left(\varepsilon / \mathrm{M}^{-1} \mathrm{~cm}^{-1}\right)$ \\
\hline $1 b^{\bullet^{+}}$ & 304(13700), 417(28200), 779(1600) \\
\hline $1 \mathrm{~b}$ & $297(15300), 365(20500), 1378(9200)$ \\
\hline $1 \mathrm{~b}^{--}$ & $306(17600), 392(18500), 500(4000), 582(5600), 635(5000), 805(1900)$ \\
\hline $1 b^{2-}$ & 309(17100), 392sh \\
\hline $2 \mathbf{b}^{0^{+}}$ & 298(7000), 402(12800), 420(13700), 478(8800), $537(3800), 567(4500), 790(1800), 1017 \mathrm{sh}$ \\
\hline 2b & $319(8400), 390(9300), 477(2100), 650(1700), 970(9500)$ \\
\hline$\left[\mathrm{Pt}(\text { pap}) \mathrm{Cl}_{2}\right]^{-,}, 44$ & $302(13800), 345 \mathrm{sh}, 367(15600), 380 \mathrm{sh}, 425 \mathrm{sh}, 480(4100), 592(1600)$ \\
\hline $2 \mathbf{b}^{2-}+\mathrm{c}^{-2}$ & $310(12000), 395(5800), 504(1800)$ \\
\hline$\left[\mathrm{Pt}(\text { pap}) \mathrm{Cl}_{2}\right]^{2-,}, 44$ & $355(10900), 490 \mathrm{sh}$ \\
\hline $3 \mathbf{b}^{+}$ & $304(11300), 420(20800), 568 \mathrm{sh}, 740(1700)$ \\
\hline 3b & $300(13100), 371(16300), 1208(6000)$ \\
\hline $3 \mathbf{b}^{\mathbf{0}^{-}}$ & $309(14900), 390(18200), 580(6800), 635 \mathrm{sh}, 775(2100)$ \\
\hline
\end{tabular}




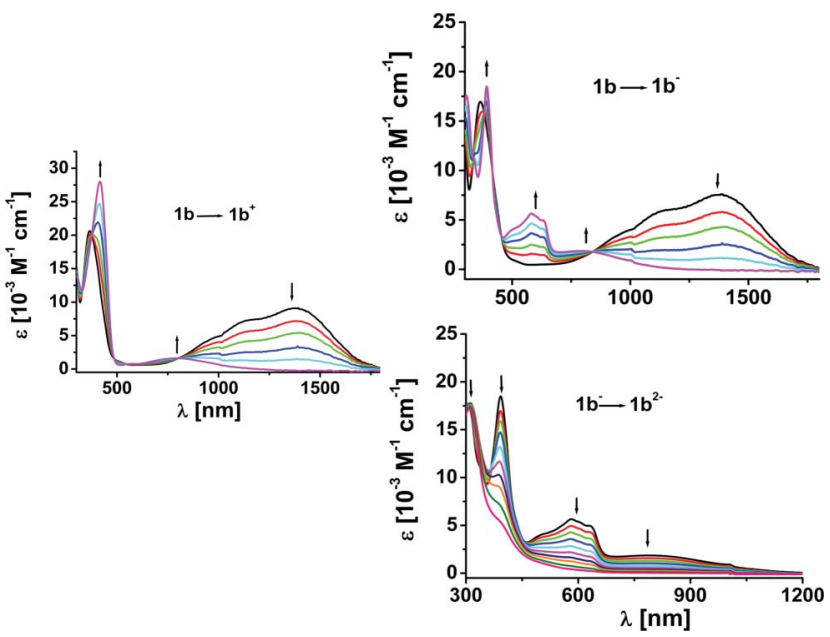

Fig. 3 Changes in the vis-NIR spectrum of $\mathbf{1 b}$ during the various redox processes in $\mathrm{CH}_{2} \mathrm{Cl}_{2} / 0.1 \mathrm{M} \mathrm{Bu}_{4} \mathrm{NPF}_{6}$ at $298 \mathrm{~K}$.
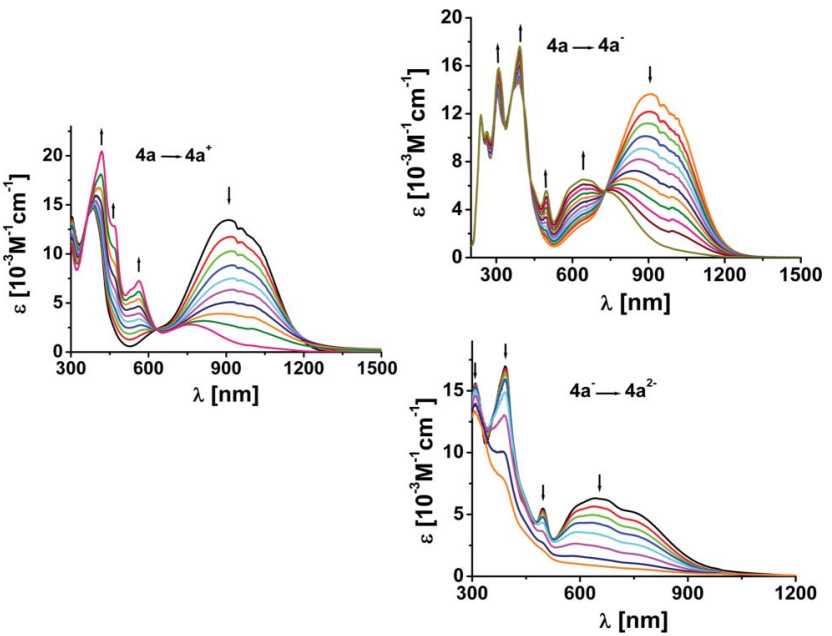

Fig. 4 Changes in the vis-NIR spectrum of $\mathbf{4 a}$ during the various redox processes in $\mathrm{CH}_{2} \mathrm{Cl}_{2} / 0.1 \mathrm{M} \mathrm{Bu}_{4} \mathrm{NPF}_{6}$ at $298 \mathrm{~K}$.

of the precursor complexes $\left[\mathrm{Pd}(\mathrm{pap}) \mathrm{Cl}_{2}\right]$ and $\left[\mathrm{Pt}(\mathrm{pap}) \mathrm{Cl}_{2}\right]$ thus helping in their assignment. ${ }^{44}$

One-electron oxidation of the complexes in $\mathrm{CH}_{2} \mathrm{Cl}_{2} / 0.1 \mathrm{M}$ $\mathrm{Bu}_{4} \mathrm{NPF}_{6}$ in an optically transparent thin layer electrochemical (OTTLE) ${ }^{45}$ cell leads to depletion and diminishing of intensity of the NIR bands. Additionally, new intense bands appear between 400 and $500 \mathrm{~nm}$ (for example at $468 \mathrm{~nm}$ for $\mathbf{4 a}^{-+}$). These bands are typically observed as IL transitions for the semiquinone $\mathrm{Q}^{-}$ radical, ${ }^{8,46,47}$ thus indicating that the oxidation process occurs primarily at the $\mathrm{Q}^{2-}$ center, resulting in $\left[\left(\mathrm{Q}^{--}\right) \mathrm{M}^{\mathrm{II}}\left(\mathrm{pap}^{0}\right)\right]^{++}$. Other bands of the MLCT and LLCT nature are also seen for the one-electron oxidized forms of the complexes. Even though the second oxidation processes could not be investigated owing to their irreversible nature, attempts at generating these species showed a complete depletion of bands in the vis-NIR region as would be expected for the formation of a $\left[\left(\mathrm{Q}^{0}\right) \mathrm{M}^{\mathrm{II}}\left(\mathrm{pap}^{0}\right)\right]^{2+}$ complex.

One-electron reduction also leads to diminishing of intensity of the NIR absorptions. Additionally, multiple bands appear in the visible region that can be assigned to MLCT and IL transitions of a metal bound azo radical (Fig. 3 and 4, Table 3). Confidence in this assignment comes from the spectra of $\left[\mathrm{Pd}^{\mathrm{II}}\left(\mathrm{pap}^{--}\right) \mathrm{Cl}_{2}\right]^{-}$
Table 4 EPR data of the paramagnetic complexes ${ }^{a}$

\begin{tabular}{lllll}
\hline Compound & $g_{\text {iso }}$ & $a_{\text {iso }}\left({ }^{1} \mathrm{H}\right)^{b}$ & $a_{\text {iso }}\left({ }^{14} \mathrm{~N}\right)^{b}$ & $a_{\text {iso }}(\mathrm{M})^{b}$ \\
\hline $\mathbf{b}^{\cdot+}$ & 2.002 & 3.3 & n.o. & $2.2^{e}$ \\
$\mathbf{1 b}^{++, c}$ & 2.002 & 3.4 & $0.3,0.2,0.1$ & 1.7 \\
$\mathbf{1 b}^{-}$ & 2.004 & n.o. & $9.0,3.1,2.6^{d}$ & $3.0^{e}$ \\
$\mathbf{1 b}^{-,-c}$ & 2.004 & 0.7 & $3.6,1.0,0.8$ & 6.0 \\
$\mathbf{2 a}^{\cdot+, 18}$ & 1.994 & 3.6 & n.o. & $24.5^{f}$ \\
$\mathbf{2 a}^{++, c}$ & 1.992 & 3.5 & $1.1,0.6,0.8$ & $15.8^{f}$ \\
$\mathbf{2 a}^{-\cdot, 18}$ & 2.005 & n.o. & n.o. & $104.0^{f}$ \\
$\mathbf{2 a}^{--, c}$ & 2.006 & 2.6 & $3.4,0.9,0.6$ & $90.0^{f}$ \\
$\mathbf{3 b}^{++}$ & 2.001 & 3.7 & n.o. & $2.3^{e}$ \\
$\mathbf{3 b}^{-}$ & 2.003 & n.o. & $8.6,3.4,2.8^{d}$ & $3.5^{e}$ \\
$\mathbf{4 a}^{-+}$ & 1.995 & 3.6 & n.o. & $22.2^{f}$ \\
$\mathbf{4 a}^{--}$ & 2.005 & n.o. & n.o. & $108.0^{f}$
\end{tabular}

${ }^{a} \mathrm{X}$-band EPR data obtained from in situ generated species in $\mathrm{CH}_{2} \mathrm{Cl}_{2} / 0.1$ $\mathrm{M} \mathrm{Bu}_{4} \mathrm{NPF}_{6}$ at $298 \mathrm{~K}$. ${ }^{b}$ Isotropic hyperfine coupling constants in Gauss obtained from simulation. ${ }^{c}$ Calculated using $\mathrm{ADF} / \mathrm{BP}$ at optimized geometry. ${ }^{d}$ Hyperfine coupling constants of nitrogen atoms belonging to the azo group and pyridine ring of pap. ${ }^{e}$ Hyperfine coupling to ${ }^{105} \mathrm{Pd}$, $I=5 / 2$, natural abundance $=22.2 \% .{ }^{f}$ Hyperfine coupling to ${ }^{195} \mathrm{Pt}, I=\frac{1}{2}$, natural abundance $=33.3 \%$.

and $\left[\mathrm{Pt}^{\mathrm{II}}\left(\mathrm{pap}^{--}\right) \mathrm{Cl}_{2}\right]^{--}$which shows very similar transitions in the visible region. ${ }^{39}$ Thus the reduction takes place primarily on the pap center leading to complexes of the form $\left[\left(\mathrm{Q}^{2-}\right) \mathrm{M}^{\mathrm{II}}\left(\mathrm{pap}^{\boldsymbol{0}^{-}}\right)\right]^{{ }^{-}}$. On further one-electron reduction, almost all the bands in the visible and NIR region lose their intensity as would be expected for the formation of $\left[\left(\mathrm{Q}^{2-}\right) \mathrm{M}^{\mathrm{II}}\left(\mathrm{pap}^{2-}\right)\right]^{2-}$.

The NIR bands observed for the neutral complexes $\mathbf{1 b}-\mathbf{3 b}$ and 4a dominate their spectra. The position of these bands can be tuned by changing the metal centers as well as the Q ligand (Table 3) and the band positions correlate well with the difference between the 1st oxidation and 1st reduction potentials of these complexes. Reversible one-electron oxidation as well as reduction leads to almost complete depletion of these bands as seen above. Thus, a simple electron transfer can lead to the change in intensity of these NIR bands from extinction coefficient values of about $10000 \mathrm{M}^{-1} \mathrm{~cm}^{-1}$ to almost 0 . The redox processes, particularly the first oxidation occur at extremely low and accessible potentials. Compounds with such characteristics have been postulated as useful candidates for future opto-electronic systems. ${ }^{40}$

\section{EPR spectroelectrochemistry}

In order to further consolidate the assignment of redox processes made by vis-NIR spectroelectrochemistry, EPR spectroscopy was carried out on the odd-electron forms of the complexes. The substances for carrying out the EPR measurements were generated by in situ electrolysis of the neutral complexes in $\mathrm{CH}_{2} \mathrm{Cl}_{2} / 0.1 \mathrm{M} \mathrm{Bu}_{4} \mathrm{NPF}_{6}$. The one-electron oxidized form $\mathbf{1 b}^{\cdot+}$ shows a well resolved signal at $298 \mathrm{~K}$ centered at $g=2.002$ (Fig. 5 and Table 4). This spectrum could be simulated by considering hyperfine coupling to one ${ }^{1} \mathrm{H}$ nucleus $\left(I=\frac{1}{2}\right)$ of $3.3 \mathrm{G}$ and one ${ }^{105} \mathrm{Pd}$ nucleus $(I=5 / 2$, natural abundance $=22.2 \%$ ) of $2.2 \mathrm{G}$. The ${ }^{105} \mathrm{Pd}$ satellites are visible on the extremities of the experimental signal. The $g$-value and the hyperfine coupling constants are typical for a metal bound semiquinone radical thus pointing to a form $\left[(\mathrm{Q})^{-}-\mathrm{Pd}^{\mathrm{II}}\left(\mathrm{pap}^{0}\right)\right]^{{ }^{+}}$for the one-electron oxidized species. 

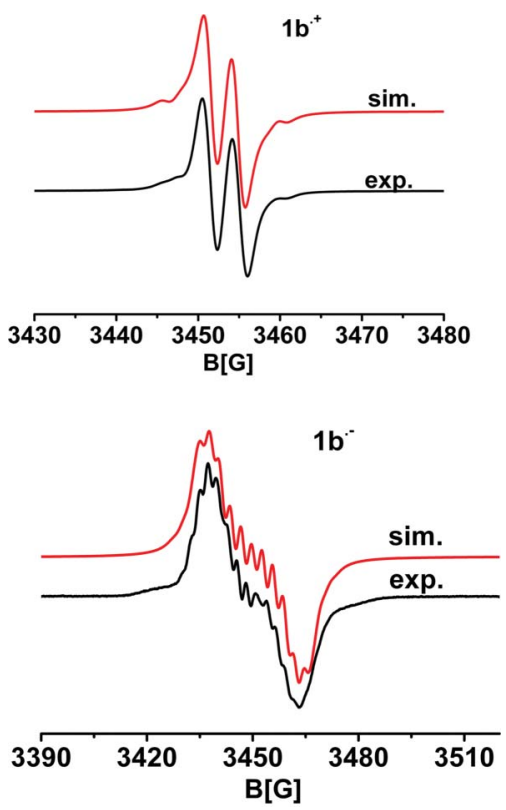

Fig. 5 X-band EPR spectrum of in situ generated $\mathbf{1 b}^{\cdot+}$ and $\mathbf{1 b}^{-\boldsymbol{*}}$ at $298 \mathrm{~K}$ in $\mathrm{CH}_{2} \mathrm{Cl}_{2} / 0.1 \mathrm{M} \mathrm{Bu}_{4} \mathrm{NPF}_{6}$ together with simulation.

The one-electron oxidized platinum complex $4 \mathbf{4}^{\cdot+}$ shows a spectrum centered at $g=1.995$, that is similar in features to that of $\mathbf{1} \mathbf{b}^{\mathbf{*}}$. The only difference being the observance of ${ }^{195} \mathrm{Pt}$ ( $I=$ $1 / 2$, natural abundance $=33.3 \%$ ) satellites instead of palladium satellites (Fig. 6). This spectrum could be simulated by using a hyperfine coupling of $3.6 \mathrm{G}$ to the ${ }^{1} \mathrm{H}$ nucleus and of $22.2 \mathrm{G}$ to the ${ }^{195} \mathrm{Pt}$ nucleus. The much larger hyperfine coupling constant to the ${ }^{195} \mathrm{Pt}$ nucleus in the case of $\mathbf{4 a}^{\cdot+}$ as compared to the hyperfine coupling to ${ }^{105} \mathrm{Pd}$ in the case of $\mathbf{1} \mathbf{b}^{\mathbf{}+}$ is due to the larger isotropic hyperfine coupling constant value for ${ }^{195} \mathrm{Pt}(1227.8 \mathrm{mT})$
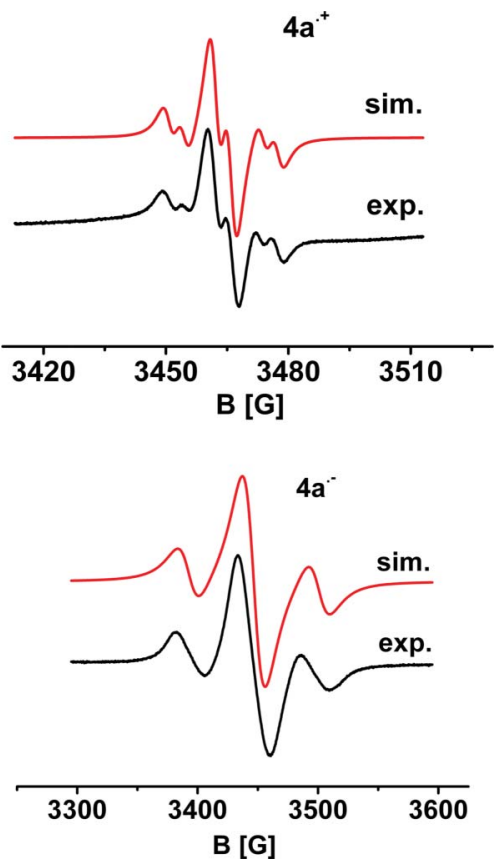

Fig. $6 \mathrm{X}$-band EPR spectrum of in situ generated $\mathbf{4 a}^{\cdot+}$ and $\mathbf{4 a ^ { * - }}$ at $298 \mathrm{~K}$ in $\mathrm{CH}_{2} \mathrm{Cl}_{2} / 0.1 \mathrm{M} \mathrm{Bu}_{4} \mathrm{NPF}_{6}$ together with simulation. as compared to ${ }^{105} \mathrm{Pd}(-2.683 \mathrm{mT}) .^{48}$ Thus $\mathbf{4 a ^ { * + }}$ can be formulated as $\left[(\mathrm{Q})^{--} \mathrm{Pt}^{\mathrm{II}}\left(\operatorname{pap}^{0}\right)\right]^{\cdot+} \cdot{ }^{18}$

The one-electron reduced form $\mathbf{1} \mathbf{b}^{\mathbf{}^{-}}$shows a signal centered at $g=2.004$ at $298 \mathrm{~K}$. This spectrum shows multiple lines which could be reasonably simulated by using hyperfine coupling to three different ${ }^{14} \mathrm{~N}(I=1)$ nuclei of 9.0,3.1 and $2.6 \mathrm{G}$ respectively as well as a ${ }^{105} \mathrm{Pd}$ coupling of $3 \mathrm{G}$ (Fig. 5). An unambiguous assignment of the nitrogen coupling to specific nitrogen atoms is not possible. However, it can be said with a reasonable amount of confidence that the largest coupling of $9.0 \mathrm{G}$ is probably to the nitrogen atom of the azo part which is coordinated to the palladium center. The compound $\mathbf{4 a}^{--}$shows a signal at $298 \mathrm{~K}$ which is centered at $g=2.005$. This spectrum could be simulated by considering a ${ }^{195} \mathrm{Pt}$ coupling of $108 \mathrm{G}$ (Fig. 6). The large line-width of this signal which is associated with the large ${ }^{195} \mathrm{Pt}$ hyperfine coupling precludes the resolution of the ${ }^{14} \mathrm{~N}$ coupling for the platinum complex. The much larger ${ }^{195} \mathrm{Pt}$ coupling for the reduced form as compared to the oxidized form has to do with a large amount of back donation that is possible from the $\mathrm{Pt}$ (II) center to the pap ligand. The EPR data thus unambiguously establish the one-electron reduced forms as $\left[(\mathrm{Q})^{2-} \mathrm{M}^{\mathrm{II}}\left(\text { pap }^{\cdot-}\right)\right]^{--}$.

\section{DFT calculations}

The DFT optimized bond lengths and angles of $\mathbf{1 b}$ and $\mathbf{2 b}$ well describe the experimental crystal structures (Table $\mathrm{S} 1 \uparrow$ ), bond lengths are reproduced within $0.02 \AA$ with an exception of the N3-C15 bond. Positional isomers b have slightly lower energy than a, free energy differences are 0.013 and $0.020 \mathrm{eV}$ for $\mathbf{1 b}$ and $\mathbf{2 b}$, respectively.

Frontier molecular orbitals (FMO) of $\mathbf{2 b}$ are depicted in Figure S3†, shapes of FMOs of $\mathbf{1 b}$ differ only slightly. HOMOs of both complexes are formed by the $\pi$ system of the $\mathrm{Q}$ ligand with some $\mathrm{M}$ contribution. LUMOs are composed of a $\pi$ pap orbital with a contributing metal $\mathrm{d}_{x z}$ orbital $(12 \%$ and $8.5 \%$ for $\mathrm{Pt}$ and $\mathrm{Pd}$ complex, respectively). In the course of oxidation an electron is withdrawn from the $\mathrm{Q}$ based $\mathrm{MO}$, during the reduction an electron is accepted in preferably the pap localized orbital with partly contributing metal orbital. Fig. 7 depicts spin densities for oxidized and reduced forms of $\mathbf{2} \mathbf{b}$; analogous shapes are obtained in the case of $\mathbf{1 b}$.

ADF/BP calculated spin densities on Pt are 0.014 and 0.147 for oxidized and reduced species, respectively. Spin densities on $\mathrm{Pd}$ are 0.009 and 0.080 in the case of oxidized and reduced species, respectively. Spin density distribution is reflected by the calculated EPR parameters. Calculated $g$ values and hyperfine couplings for radical cations and anions of both complexes are listed in Table 4. The calculated EPR parameters correlate well with the experimental ones. The ratio between $a_{\text {iso }}(\mathrm{Pd})$ and $a_{\text {iso }}(\mathrm{Pt})$ is reasonably well interpreted; calculations underestimate $a_{\text {iso }}(\mathrm{Pt})$ and overestimate the $a_{\text {iso }}(\mathrm{Pd})$ parameter of $\mathbf{1}^{-\mathbf{b}^{-}}$.

TD-DFT calculations well interpret the experimental spectral features of $\mathbf{2 b}$ (Table 5 and $\mathrm{S} 3 \dagger$ ). The intense allowed feature calculated at $841 \mathrm{~nm}$ can be characterized as a LLCT $\left(\mathrm{Q}^{2-}\right.$ to pap $^{0}$ ) transition. A second intense transition calculated at $373 \mathrm{~nm}$ has mixed MLCT and IL character and also well reproduces the experimental feature. Shifts of lowest lying allowed transitions to shorter wavelengths and the intensity variations are well reproduced by calculations for oxidized and reduced species. 
Table 5 Main TD-DFT (PRE0/PCM-CH $\mathrm{Cl}_{2}$ ) calculated transitions of $\mathbf{1} \mathbf{b}^{n}$ and $\mathbf{2} \mathbf{b}^{n}$ compared with experimental data

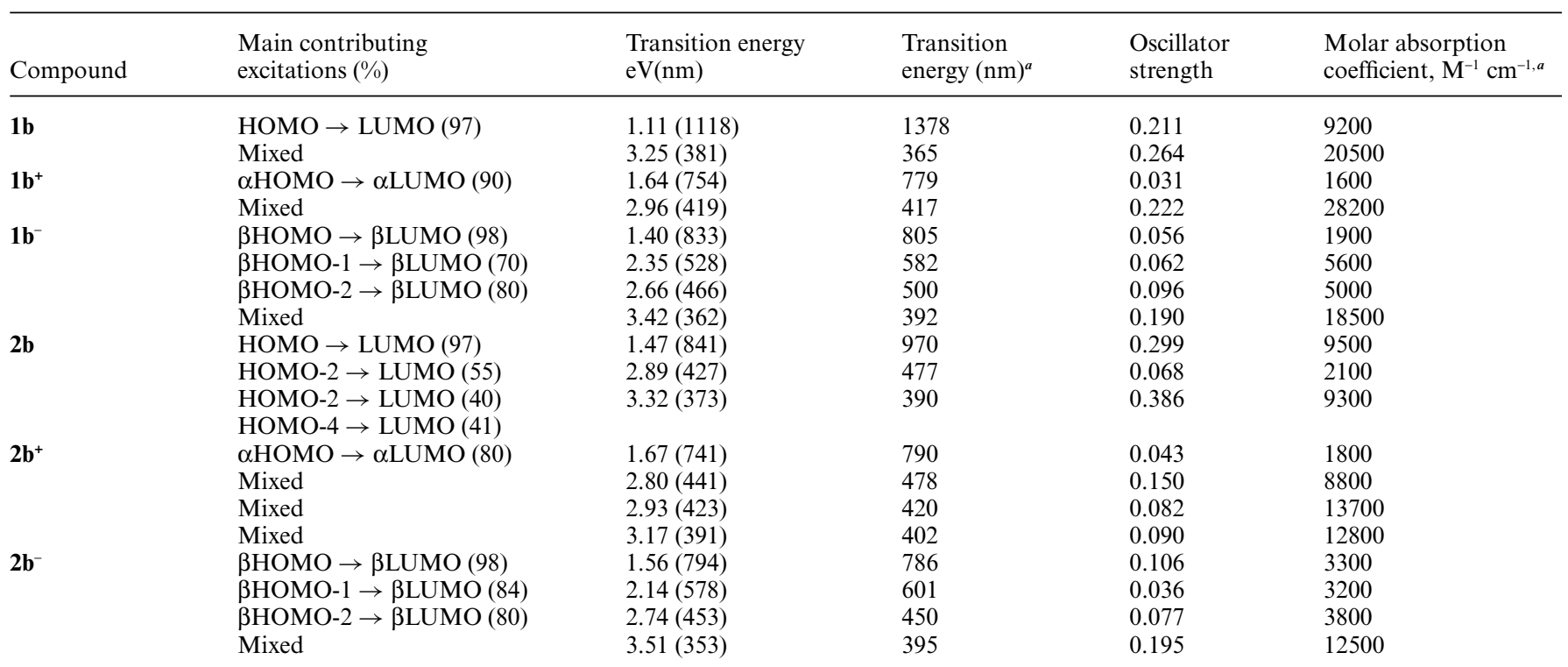

${ }^{a}$ From OTTLE spectroelectrochemistry in $\mathrm{CH}_{2} \mathrm{Cl}_{2} / 0.1 \mathrm{M} \mathrm{Bu}_{4} \mathrm{NPF}_{6}$.
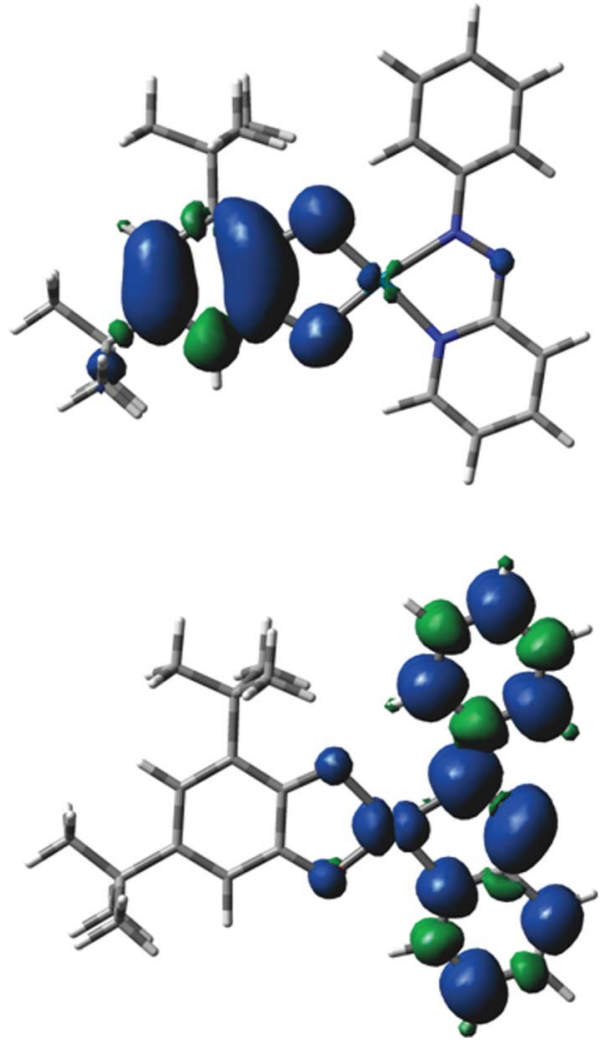

Fig. 7 Spin density plots of $\mathbf{1 b}^{\boldsymbol{0}^{+}}$and $\mathbf{1} \mathbf{b}^{\cdot-}$ from DFT calculations.

FMOs contributing to lowest lying intense transitions in $\mathbf{2} \mathbf{b}^{+}$and $\mathbf{2 b}^{-}$are depicted in Figures $\mathrm{S} 4$ and $\mathrm{S} 5 \dagger$.

TD-DFT calculated transitions for $\mathbf{1 b}$, listed in Table 5 and $\mathrm{S} 2 \uparrow$, also well interpret the experimental spectral features. In agreement with experimental finding lowest lying excitations for $\mathbf{1 b}$ are calculated at longer wavelengths than in $\mathbf{2 b}$.

\section{Conclusion}

By combining two different non-innocent ligands we were able to characterize donor acceptor systems of the form $\left[\left(\mathrm{Q}^{n}\right) \mathrm{M}^{\mathrm{II}}\left(\operatorname{pap}^{m}\right)\right]$, $\mathrm{M}=\mathrm{Pd}$ or $\mathrm{Pt} ; n=-1,-2 ; m=0,-1,-2$. The in-built asymmetry of the ligands makes isomer formation possible and these could be isolated by using thermodynamic versus kinetic reaction control as well as solubility differences. Structural characterization of $\mathbf{1 b}$ was used for isomer identification. Bond length analyses in $\mathbf{1 b}$ lead to the formulation $\left[\left(\mathrm{Q}^{2-}\right) \mathrm{Pd}^{\mathrm{II}}\left(\mathrm{pap}^{0}\right)\right]$ for the neutral complexes. All the complexes show two one-electron oxidation and two oneelectron reduction processes. Additionally, the neutral forms of all the complexes show strong absorptions in the NIR region which can be tuned by changing the metal center and the $\mathrm{Q}$ ligand. The intensity of the NIR bands can be influenced by electron transfer processes. The oxidation of the complexes occur predominantly on the $\mathrm{Q}^{2-}$ ligand generating successively metal bound $\mathrm{Q}^{--}$and $\mathrm{Q}^{0}$. The identity of these forms was verified through the typical metalbound semiquinone absorption bands in the visible region of the absorption spectrum as well as through hyperfine coupling to the ${ }^{1} \mathrm{H}$ center of the semiquinone ring in the EPR spectrum. The ligand in the $\mathrm{Q}^{0}$ form does not bind well to the metal center, thus making the second oxidation step irreversible. Reduction takes place on the pap part of the complex generating successively metal-bound pap ${ }^{\cdot-}$ and pap $^{2-}$. The identity of these species was also verified through vis-NIR and EPR spectroscopy. DFT studies corroborate the experimental findings. The presence of two redox-active ligands in the same metal complex as well as a four-coordinated metal center provides opportunities in such complexes for studies of ligand redox-induced reactivity at the metal centers. Our current studies are focussed in these directions. 


\section{Experimental section}

\section{General considerations}

$\mathrm{Pd}$ (pap) $\mathrm{Cl}_{2}, \mathrm{Pt}$ (pap) $\mathrm{Cl}_{2},{ }^{44} \mathbf{2} \mathbf{a}^{18}$ and $\mathbf{2} \mathbf{b}^{18}$ were prepared according to reported procedures. All other reagents are commercially available and were used as received. All solvents were dried and distilled using common techniques unless otherwise mentioned.

\section{Instrumentation}

${ }^{1} \mathrm{H}$ NMR spectra were recorded at $250.13 \mathrm{MHz}$ on a Brucker AC250 instrument. EPR spectra in the $\mathrm{X}$ band were recorded with a Bruker System EMX. Simulations of EPR spectra were done using the Simfonia program. UV-vis-NIR absorption spectra were recorded on a J\&M TIDAS spectrometer. Cyclic voltammetry was carried out in $0.1 \mathrm{M} \mathrm{Bu} \mathrm{BPF}_{6}$ solution using a threeelectrode configuration (glassy carbon working electrode, $\mathrm{Pt}$ counter electrode, Ag wire as pseudoreference) and PAR 273 potentiostat and function generator. The ferrocene/ferrocenium $\left(\mathrm{Fc} / \mathrm{Fc}^{+}\right)$couple served as internal reference. Spectroelectrochemical measurements were carried out using an optically transparent thin layer electrochemical (OTTLE) cell. Elemental analysis was performed on a Perkin Elmer Analyser 240. Mass spectrometry experiments were carried out on a Bruker Daltronics Mictrotof-Q mass spectrometer.

\section{Syntheses}

1a. $\mathrm{Pd}($ pap $) \mathrm{Cl}_{2}(72.1 \mathrm{mg}, 0.20 \mathrm{mmol})$ and 3,5-di-tert-butyl catechol (44.4 mg, $0.20 \mathrm{mmol})$ were taken together in $20 \mathrm{~mL}$ of acetonitrile. Triethylamine $(0.1 \mathrm{ml})$ was added to the solution. The reaction mixture was stirred at room temperature for $3 \mathrm{~h}$. The green precipitate was filtered, washed with diethylether and purified by column chromatography on aluminiumoxide $\left(\mathrm{CH}_{2} \mathrm{Cl}_{2} / \mathrm{CH}_{3} \mathrm{CN}\right.$ : 10/1). Yield: $50.0 \mathrm{mg}(49 \%) .{ }^{1} \mathrm{H}-\mathrm{NMR}\left(250 \mathrm{MHz}, \mathrm{CDCl}_{3}\right): \delta=$ 1.27 (s, 9H, tert-butyl); 1.46 (s, 9H, tert-butyl); $6.58(\mathrm{~m}, 1 \mathrm{H}$, catecholate); $6.72\left(\mathrm{~d}, 1 \mathrm{H},{ }^{4} J_{H-H}=2.17 \mathrm{~Hz}\right.$, catecholate); $7.52(\mathrm{~m}$, $4 \mathrm{H}) ; 7.96(\mathrm{~m}, 1 \mathrm{H}) ; 8.06(\mathrm{~m}, 1 \mathrm{H}) ; 8.59(\mathrm{~m}, 2 \mathrm{H}) ; 8.97(\mathrm{~m}, 1 \mathrm{H})$. Anal. Calc. for $\mathrm{C}_{25} \mathrm{H}_{29} \mathrm{~N}_{3} \mathrm{O}_{2} \mathrm{Pd}$ : C 58.88; $\mathrm{H} 5.73$; $\mathrm{N} \mathrm{8.24 \%}$; found: C 58.75; H 5.36; N 8.16\%. HRMS (ESI): Calc. for $\mathrm{C}_{25} \mathrm{H}_{29} \mathrm{~N}_{3} \mathrm{O}_{2} \mathrm{Pd}$ $\left([\mathrm{M}]^{+}\right): m / z$ 509.1299; found 509.1284.

1b. $\mathrm{Pd}($ pap $) \mathrm{Cl}_{2}(72.1 \mathrm{mg}, 0.20 \mathrm{mmol})$ and 3,5-di-tert-butyl catechol (44.4 mg, $0.20 \mathrm{mmol}$ ) were taken together in $20 \mathrm{ml}$ of acetonitrile. Triethylamine $(0.1 \mathrm{ml})$ was added to the solution. The reaction mixture was heated to $70{ }^{\circ} \mathrm{C}$ for $1 \mathrm{~h}$. After cooling to room temperature a green precipitate was formed. The precipitate was filtered, washed with diethylether and purified by column chromatography on aluminium oxide $\left(\mathrm{CH}_{2} \mathrm{Cl}_{2} / \mathrm{CH}_{3} \mathrm{CN}\right.$ : 10/1). Yield: $39.3 \mathrm{mg}(38 \%)$. ${ }^{1} \mathrm{H}-\mathrm{NMR}\left(250 \mathrm{MHz}, \mathrm{CDCl}_{3}\right): \delta=1.30(\mathrm{~s}$, $9 \mathrm{H}$, tert-butyl); 1.49 (s, 9H, tert-butyl); $6.61\left(\mathrm{~d}, 1 \mathrm{H},{ }^{4} J_{H-H}=2.20 \mathrm{~Hz}\right.$, catecholate); $6.76\left(\mathrm{~d}, 1 \mathrm{H},{ }^{4} J_{H-H}=2.20 \mathrm{~Hz}\right.$, catecholate); $7.53(\mathrm{~m}$, 4H); 8.10 (m, 1H); 8.20 (m, 1H); 8.62 (m, 2H); 8.99 (m, 1H). Anal. Calc. for $\mathrm{C}_{25} \mathrm{H}_{29} \mathrm{~N}_{3} \mathrm{O}_{2} \mathrm{Pd}$ : C 58.88; $\mathrm{H} \mathrm{5.73;} \mathrm{N} 8.24 \%$; found: C 58.81; $\mathrm{H}$ 5.67; N 8.17\%. HRMS (ESI): Calc. for $\mathrm{C}_{25} \mathrm{H}_{29} \mathrm{~N}_{3} \mathrm{O}_{2} \mathrm{Pd}\left([\mathrm{M}]^{+}\right)$: $\mathrm{m} / z$ 509.1299; found 509.1292. Recrystallization by evaporation of a dichloromethane/ $n$-hexane (1/3) solution afforded dark green crystals of $\mathbf{1 b}$. 3a. Similar to 1a by using $\mathrm{Pd}(\mathrm{pap}) \mathrm{Cl}_{2}(72.1 \mathrm{mg}, 0.20 \mathrm{mmol})$ and 4-tert-butyl catechol (33.2 mg, $0.20 \mathrm{mmol})$. Yield: $67.1 \mathrm{mg}$ (74\%). ${ }^{1} \mathrm{H}-\mathrm{NMR}\left(250 \mathrm{MHz}, \mathrm{CDCl}_{3}\right): \delta=1.28$ (s, 9H, tert-butyl); $6.59\left(\mathrm{~m}, 2 \mathrm{H}\right.$, catecholate); $6.74\left(\mathrm{dd}, 1 \mathrm{H},{ }^{3} J_{H-H}=7.38 \mathrm{~Hz},{ }^{4} J_{H-H}=\right.$ $2.05 \mathrm{~Hz}$, catecholate); 7.54 (m, 4H); 8.08 (m, 2H); 8.51 (m, 2H); $8.95(\mathrm{~m}, 1 \mathrm{H})$. Anal. Calc. for $\mathrm{C}_{21} \mathrm{H}_{21} \mathrm{~N}_{3} \mathrm{O}_{2} \mathrm{Pd}$ : C 55.58; $\mathrm{H}$ 4.66; $\mathrm{N}$ 9.26\%; found: C 55.27; H 4.61; N 9.11\%. HRMS (ESI): Calc. for $\mathrm{C}_{21} \mathrm{H}_{21} \mathrm{~N}_{3} \mathrm{O}_{2} \mathrm{Pd}\left([\mathrm{M}]^{+}\right): m / z$ 453.0671; found 453.0698 .

3b. Similar to 1b by using $\mathrm{Pd}(\mathrm{pap}) \mathrm{Cl}_{2}(72.1 \mathrm{mg}, 0.2 \mathrm{mmol})$ and 4-tert-butyl catechol (33.2 mg, $0.2 \mathrm{mmol})$. Yield: $19.2 \mathrm{mg}$ (21\%). ${ }^{1} \mathrm{H}$ NMR (250 MHz, $\left.\mathrm{CDCl}_{3}\right): \delta=1.29$ (s, 9H, tert-butyl); $6.60\left(\mathrm{~m}, 2 \mathrm{H}\right.$, catecholate); $6.78\left(\mathrm{dd}, 1 \mathrm{H},{ }^{3} J_{H-H}=4.65 \mathrm{~Hz},{ }^{4} J_{H-H}=\right.$ $2.10 \mathrm{~Hz}$, catecholate); $7.58(\mathrm{~m}, 4 \mathrm{H}) ; 8.12(\mathrm{~m}, 2 \mathrm{H}) ; 8.52(\mathrm{~m}, 2 \mathrm{H})$; $8.99(\mathrm{~m}, 1 \mathrm{H})$. Anal. Calc. for $\mathrm{C}_{21} \mathrm{H}_{21} \mathrm{~N}_{3} \mathrm{O}_{2} \mathrm{Pd}$ : C 55.58; $\mathrm{H} 4.66 ; \mathrm{N}$ 9.26\%; found: C 55.31; H 4.51; N 9.06\%. HRMS (ESI): Calc. for $\mathrm{C}_{21} \mathrm{H}_{21} \mathrm{~N}_{3} \mathrm{O}_{2} \mathrm{Pd}\left([\mathrm{M}]^{+}\right): m / z$ 453.0671; found 453.0684.

4a and 4b. $\operatorname{Pt}($ pap $) \mathrm{Cl}_{2}(44.9 \mathrm{mg}, 0.1 \mathrm{mmol})$ and 4-tert-butyl catechol (16.6 mg, $0.1 \mathrm{mmol})$ were taken together in $15 \mathrm{~mL}$ of acetonitrile. Triethylamine $(0.1 \mathrm{ml})$ was added to the solution. The reaction mixture was heated to reflux for $3 \mathrm{~h}$. The colour of the solution changed to deep green. The precipitate that formed was filtered and washed with diethylether. This compound corresponds to 4a. The filtrate was collected and the solvent evaporated. The crude product was purified by column chromatography on silica gel $\left(\mathrm{CH}_{2} \mathrm{Cl}_{2} / \mathrm{CH}_{3} \mathrm{CN}\right.$ : 10/1). First green band corresponds to the compound $\mathbf{4 b}$.

4a. Yield: $24.2 \mathrm{mg}(44 \%) .{ }^{1} \mathrm{H}-\mathrm{NMR}\left(250 \mathrm{MHz}, \mathrm{CDCl}_{3}\right): \delta=$ 1.32 (s, 9H, tert-butyl); $6.64(\mathrm{~m}, 1 \mathrm{H}$, catecholate); $6.99(\mathrm{~m}, 1 \mathrm{H}$, catecholate); $7.12\left(\mathrm{dd}, 1 \mathrm{H},{ }^{3} J_{H-H}=6.59 \mathrm{~Hz},{ }^{4} J_{H-H}=2.19 \mathrm{~Hz}\right.$, catecholate); $7.58(\mathrm{~m}, 4 \mathrm{H}) ; 8.04(\mathrm{~m}, 1 \mathrm{H}) ; 8.24(\mathrm{~m}, 1 \mathrm{H}) ; 8.56(\mathrm{~m}$, $2 \mathrm{H})$; 9.65 (m, 1H). Anal. Calc. for $\mathrm{C}_{21} \mathrm{H}_{21} \mathrm{~N}_{3} \mathrm{O}_{2} \mathrm{Pt}$ : C 46.49; $\mathrm{H} 3.90$; N 7.75\%; found: C 45.94; $\mathrm{H} 3.88$; N 7.59\%. HRMS (ESI): Calc. for $\mathrm{C}_{21} \mathrm{H}_{21} \mathrm{~N}_{3} \mathrm{O}_{2} \mathrm{Pt}\left([\mathrm{M}]^{+}\right): m / z$ 542.1278; found 542.1273.

4b. Yield: $12.3 \mathrm{mg}(22 \%) .{ }^{1} \mathrm{H}-\mathrm{NMR}\left(250 \mathrm{MHz}, \mathrm{CDCl}_{3}\right): \delta=$ 1.32 (s, 9H, tert-butyl); $6.64(\mathrm{~m}, 1 \mathrm{H}$, catecholate); $6.98(\mathrm{~m}, 1 \mathrm{H}$, catecholate); $7.11\left(\mathrm{dd}, 1 \mathrm{H},{ }^{3} J_{H-H}=6.73 \mathrm{~Hz},{ }^{4} J_{H-H}=2.20 \mathrm{~Hz}\right.$, catecholate); $7.57(\mathrm{~m}, 4 \mathrm{H}) ; 8.01(\mathrm{~m}, 1 \mathrm{H}) ; 8.23(\mathrm{~m}, 1 \mathrm{H}) ; 8.54(\mathrm{~m}$, $2 \mathrm{H}) ; 9.63(\mathrm{~m}, 1 \mathrm{H})$. Anal. Calc. for $\mathrm{C}_{21} \mathrm{H}_{21} \mathrm{~N}_{3} \mathrm{O}_{2} \mathrm{Pt}$ : C 46.49; $\mathrm{H} 3.90$; N 7.75\%; found: C 46.01; H 3.81; N 7.59\%. HRMS (ESI): Calc. for $\mathrm{C}_{21} \mathrm{H}_{22} \mathrm{~N}_{3} \mathrm{O}_{2} \mathrm{Pt}\left([\mathrm{M}+\mathrm{H}]^{+}\right): m / z$ 543.1356; found 543.1373 .

\section{X-ray crystallography}

Single crystals of $\mathbf{1 b}$ were grown by slow evaporation of a $\mathrm{CH}_{2} \mathrm{Cl}_{2}$ solution of it layered with $n$-hexane. The intensity data were collected at 173(2) $\mathrm{K}$ on a Kappa CCD diffractometer (graphite monochromated $\mathrm{MoK}_{\mathrm{a}}$ radiation, $1=0.71073 \AA$ ). The structures were solved by direct methods (SHELXS-97) and refined by full-matrix least-square procedures (based on $F^{2}$, SHELXL-97) with anisotropic thermal parameters for all the non-hydrogen atoms. ${ }^{49} \mathrm{CCDC} 805489$ contains the supplementary crystallographic data for this paper that can be obtained free of charge from the Cambridge Crystallographic Data Center via www.ccdc.cam.ac.uk/data_request/cif. 


\section{Quantum chemical calculations}

The electronic structures of $\mathbf{1 b}^{n}$ and $\mathbf{2 b}^{n}(n=-1,0,1)$ were calculated by density functional theory (DFT) methods using the Gaussian $09^{50}$ and Amsterdam Density Functional (ADF2009.01) ${ }^{51,52}$ program packages.

G09 calculations employed Perdew, Burke, Ernzerhof ${ }^{53,54}$ PBE0 hybrid functional (G09/PBE0). The geometry of the open shell systems was calculated by UKS approach. Geometry optimization was followed by vibrational analysis. For $\mathrm{H}, \mathrm{C}, \mathrm{N}$ and $\mathrm{O}$ atoms polarized triple- $\zeta$ basis sets $6-311 \mathrm{G}(\mathrm{d}),{ }^{55}$ together with quasirelativistic effective core pseudopotentials and corresponding optimized set of basis functions for Pd and Pt were used. ${ }^{56,57}$ Low-lying excitation energies were calculated by time-dependent DFT (TD-DFT) at the optimized geometry of the corresponding oxidation state. The solvent was described by the polarizable continuum model (PCM) ${ }^{58}$ in TD DFT calculations.

Within the ADF program Slater type orbital (STO) basis sets of triple- $\zeta$ quality with two polarisation functions for $\mathrm{C}, \mathrm{N}, \mathrm{O}$ and $\mathrm{H}$ atoms and quadruple- $\zeta$ with four polarisation functions for the $\mathrm{Pd}$ and $\mathrm{Pt}$ atom were employed. Core electrons were included in the calculations. Within ADF the functional including Becke's gradient correction to the local exchange expression in conjunction with Perdew's gradient correction to local density approximation (LDA) with VWN parametrisation of electron gas data was used (ADF/BP86). ${ }^{59,60} A$ and $g$ tensors were obtained by first-order perturbation theory from a ZORA Hamiltonian in the presence of a time-independent magnetic field..$^{61,62}$ The $g$ tensor was obtained from a spin-nonpolarised wave function after incorporating the spin-orbit (SO) coupling.

\section{Acknowledgements}

We are thankful to the Baden-Württemberg Stiftung, Deutsche Forschungsgemeinschaft (DFG) and the Fonds der Chemischen Industrie (FCI) for financial support. Dr R. Pattacini is kindly acknowledged for crystal structure solving. S. Z. thanks the Ministry of Education of the Czech Republic (Grant COST LD11086) and the European collaboration program COST D35.

\section{References}

1 S. D. Cummings and R. Eisenberg, J. Am. Chem. Soc., 1996, 118, 1949.

2 J. A. Zuleta, C. A. Chesta and R. Eisenberg, J. Am. Chem. Soc., 1989, 111, 8916.

3 W. B. Connick, D. Geiger and R. Eisenberg, Inorg. Chem., 1999, 38, 3264.

4 N. M. Shavaleev, G. Accorsi, D. Virgili, Z. R. Bell, T. Lazarides, G. Calogero, N. Armaroli and M. D. Ward, Inorg. Chem., 2005, 44, 61.

5 A. Vogler and H. Kunkely, J. Am. Chem. Soc., 1981, 103, 1559.

6 K. Base and M. W. Grinstaff, Inorg. Chem., 1998, 37, 1432.

7 J. A. Weinstein, N. N. Zheligovskaya, M. Y. Mel'nikov and F. Hartl, J. Chem. Soc., Dalton Trans., 1998, 2459.

8 J. A. Weinstein, M. T. Tierney, E. S. Davies, K. Base, A. A. Robeiro and M. W. Grinstaff, Inorg. Chem., 2006, 45, 4544.

9 N. M. Shavaleev, E. S. Davies, H. Adams, J. Best and J. A. Weinstein, Inorg. Chem., 2008, 47, 1532.

10 J. Best, I. V. Sazanovich, H. Adams, R. D. Bennett, E. S. Davies, A. J. H. M. Meijer, M. Towrie, S. A. Tikhomirov, O. V. Bouganov, M. D. Ward and J. A. Weinstein, Inorg. Chem., 2010, 49, 10041.

11 E. A. M. Geary, K. L. McCall, A. Turner, P. R. Murray, E. J. L. McInnes, L. A. Jack, L. J. Yellowlees and N. Robertson, Dalton Trans., 2008, 3701 .

12 K. Heinze and S. Reinhardt, Chem.-Eur. J., 2008, 14, 9482.
13 G. K. Rauth, S. Pal, D. Das, C. Sinha, A. M. Slawin and J. D. Woolins, Polyhedron, 2001, 20, 363.

14 Z. Sun, H. Chun, K. Hildebrand, E. Bothe, T. Weyhermüller, F. Neese and K. Wieghardt, Inorg. Chem., 2002, 41, 4295.

15 P. Ghosh, A. Begum, D. Herebian, E. Boethe, K. Hildenbrand, T. Weyhermüller and K. Wieghardt, Angew. Chem., Int. Ed., 2003, 42, 563.

16 S. Mondal, N. Paul, P. Banerjee, T. K. Mondal and S. Goswami, Dalton Trans., 2010, 39, 2717.

17 S. Mandal, A. Castineiras, T. K. Mondal, A. Mondal, D. Chattopadhyay and S. Goswami, Dalton Trans., 2010, 39, 9514.

18 B. Sarkar, R. Huebner, R. Pattacini and I. Hartenbach, Dalton Trans., 2009, 4653.

19 W. Kaim, Coord. Chem. Rev., 2001, 219-221, 463.

20 M. D. Ward and J. A. McCleverty, J. Chem. Soc., Dalton Trans., 2002, 275.

21 S. Bhattacharya, P. Gupta, F. Basuli and C. G. Pierpont, Inorg. Chem., 2002, 41, 5810 .

22 D. Herebian, E. Bothe, F. Neese, T. Weyhermüller and K. Wieghardt, J. Am. Chem. Soc., 2003, 125, 9116.

23 G. K. Lahiri, S. Bhattacharya, S. Goswami and A. Chakravorty, J. Chem. Soc., Dalton Trans., 1990, 561.

24 B. K. Santra, G. A. Thakur, P. Ghosh, A. Pramanik and G. K. Lahiri, Inorg. Chem., 1996, 35, 3050.

25 S. Patra, B. Sarkar, S. Maji, J. Fiedler, F. A. Urbanos, R. J.-. Aparicio, W. Kaim and G. K. Lahiri, Chem.-Eur. J., 2006, 12, 489.

26 A. I. Poddel'sky, V. K. Cherkasov and G. A. Abakomov, Coord. Chem. Rev., 2009, 253, 291.

27 C. G. Pierpont, Coord. Chem. Rev., 2001, 216-217, 95.

28 P. Zanello, Coord. Chem. Rev., 2006, 250, 2000.

29 M. Nomura, T. Cauchy and M. Fourmigué, Coord. Chem. Rev., 2010, 254, 1406.

30 B. G. d. Bonneval, K. I. M.-C. Ching, F. Alary, T.-T. Bui and L. Valade, Coord. Chem. Rev., 2010, 254, 1457.

31 P. Braunstein, D. Bubrin and B. Sarkar, Inorg. Chem., 2009, 48, 2534.

32 A. Paretzki, R. Pattacini, R. Huebner, P. Braunstein and B. Sarkar, Chem. Commun., 2010, 46, 1497.

33 H. S. Das, F. Weisser, D. Schweinfurth, C. Y.-. Su, L. Bogani, J. Fiedler and B. Sarkar, Chem.-Eur. J., 2010, 16, 2977.

34 D. Schweinfurth, H. S. Das, F. Weisser, D. Bubrin and B. Sarkar, Inorg. Chem., 2011, 50, 1150.

35 F. Weisser, R. Huebner, D. Schweinfurth and B. Sarkar, Chem.-Eur. J., $2011,17,5727$.

36 H. S. Das, A. K. Das, R. Pattacini, R. Huebner, B. Sarkar and P. Braunstein, Chem Commun., 2009, 4387.

37 A. Paretzki, H. S. Das, F. Weisser, T. Scherer, D. Bubrin, J. Fiedler, J. E. Nycx and B. Sarkar, Eur. J. Inorg. Chem., 2011, 2413.

38 N. Deibel, D. Schweinfurth, R. Huebner, P. Braunstein and B. Sarkar, Dalton Trans., 2011, 40, 431.

39 R. Roy, P. Chattopadhyay, C. Sinha and S. Chattapodhyay, Polyhedron, 1996, 15, 3361.

40 M. D. Ward, J. Solid State Electrochem., 2005, 9, 778.

41 J. Garcia-Canadas, A. P. Meacham, L. M. Peter and M. D. Ward, Angew. Chem., Int. Ed., 2003, 42, 3011.

42 B. Sarkar, S. Patra, J. Fiedler, R. B. Sunoj, D. Janardanan, G. K. Lahiri and W. Kaim, J. Am. Chem. Soc., 2008, 130, 3532.

43 B. Sarkar, S. Patra, J. Fiedler, R. B. Sunoj, D. Janardanan, S. M. Mobin, M. Niemeyer, G. K. Lahiri and W. Kaim, Angew. Chem., Int. Ed., 2005, 44, 5655.

44 S. Roy, I. Hartenbach and B. Sarkar, Eur. J. Inorg. Chem., 2009, 2553.

45 M. Krejcik, M. Danek and F. Hartl, J. Electroanal. Chem., 1991, 317, 179.

46 J. A. Zuleta, J. M. Bevilacqua, D. M. Proserpio, P. D. Harvey and R. Eisenberg, Inorg. Chem., 1992, 31, 2396.

47 A. Vogler, H. Kunkely and J. Hlavatsch, Inorg. Chem., 1984, 23, 506.

48 J. A. Weil and J. R. Bolton, 'Electron Paramagnetic Resonance', John Wiley \& Sons, Inc., Hoboken, New Jersey, 2007.

49 G. M. Sheldrick, SHELXL-97, Program for crystal structure refinement, University of Göttingen, 1997.

50 R. A. Gaussian 09, M. J. Frisch, G. W. Trucks, H. B. Schlegel, G. E. Scuseria, M. A. Robb, J. R. Cheeseman, G. Scalmani, V. Barone, B. Mennucci, G. A. Petersson, H. Nakatsuji, M. Caricato, X. Li, H. P. Hratchian, A. F. Izmaylov, J. Bloino, G. Zheng, J. L. Sonnenberg, M. Hada, M. Ehara, K. Toyota, R. Fukuda, J. Hasegawa, M. Ishida, T. Nakajima, Y. Honda, O. Kitao, H. Nakai, T. Vreven, J. A. Montgomery, 
Jr., J. E. Peralta, F. Ogliaro, M. Bearpark, J. J. Heyd, E. Brothers, K. N Kudin, V. N. Staroverov, R. Kobayashi, J. Normand, K. Raghavachari, A. Rendell, J. C. Burant, S. S. Iyengar, J. Tomasi, M. Cossi, N. Rega, J. M. Millam, M. Klene, J. E. Knox, J. B. Cross, V. Bakken, C. Adamo, J. Jaramillo, R. Gomperts, R. E. Stratmann, O. Yazyev, A. J. Austin, R. Cammi, C. Pomelli, J. W. Ochterski, R. L. Martin, K. Morokuma, V. G. Zakrzewski, G. A. Voth, P. Salvador, J. J. Dannenberg, S. Dapprich, A. D. Daniels, O. Farkas, J. B. Foresman, J. V. Ortiz, J. Cioslowski, and D. J. Fox, Gaussian, Inc., Wallingford CT, 2009.

51 G. t. Velde, F. M. Bickelhaupt, S. J. A. v. Gisbergen, C. F. Guerra, E J. Baerends, J. G. Snijders and T. Ziegler, J. Comput. Chem., 2001, 22, 931.

52 S. ADF2009.01, Theoretical Chemistry, Vrije Universiteit, Amsterdam, The Netherlands, http://www.scm.com.

53 J. P. Perdew, K. Burke and M. Ernzerhof, Phys. Rev. Lett., 1996, 77, 3865.
54 C. Adamo and V. Barone, J. Chem. Phys., 1999, 110, 6158.

55 L. A. Curtiss, M. P. McGrath, J.-P. Blaudeau, N. E. Davis, R. C. B. Jr. and L. Radom, J. Chem. Phys., 1995, 103, 6104.

56 D. Andrae, U. Häussermann, M. S. Dolg, H. and H. Preuss, Theor. Chim. Acta, 1990, 77, 123.

57 J. M. L. Martin and A. Sundermann, J. Chem. Phys., 2001, 114, 3408.

58 M. Cossi, N. Rega, G. Scalmani and V. Barone, J. Comput. Chem., 2003, 24, 669.

59 A. D. Becke, Phys. Rev. A: At., Mol., Opt. Phys., 1988, 38, 3098.

60 J. P. Perdew, Phys. Rev. B, 1986, 33, 8822.

61 E. v. Lenthe, A. v. d. Avoird and P. E. S. Wormer, J. Chem. Phys., 1997, 107, 2488.

62 E. v. Lenthe, A. v. d. Avoird and P. E. S. Wormer, J. Chem. Phys., 1998, 108, 4783 . 